\title{
Acardiac twins: A case report
}

Thapa $\mathbf{B}^{1}$, Thapa $\mathbf{M}^{2}$, Manandhar $\mathbf{R}^{3}$

${ }^{1}$ Babita Thapa, MD Resident; ${ }^{2}$ Meena Thapa, Associate Professor; ${ }^{3}$ Rosina Manandhar, Lecturer; Department of Obstetrics and Gynaecology, Kathmandu Medical College Teaching Hospital, Kathmandu, Nepal.

\section{Abstract}

Acardiac anomaly is a rare complication of multiple pregnancy. We report a case at Kathmandu Medical College Teaching Hospital. A 23-year-old multigravida was diagnosed on ultrasonography as having monochorionic monoamniotic twin pregnancy with polyhydramnios and one malformed dead foetus at 18 weeks of gestation. Hence, induction of labor was considered at 36 weeks of gestation. She delivered a macerated male (twin A). Twin B was acardiac with the upper portion consisting of a soft globular mass, the head and upper extremities were absent. The placenta was single. Autopsy revealed absence of heart in twin $\mathrm{B}$.

Key words: Acardiac twins, twin pregnancy, twin reversed arterial perfusion sequence

\section{INTRODUCTION}

A cardiac twin, also referred to as the twin reversed arterial perfusion (TRAP) sequence, likely represents an extreme manifestation of the twin transfusion syndrome and has an incidence of approximately one percent in monozygotic twins or one in 35,000 deliveries ${ }^{1}$. It is characterized by lack of heart development associated with a spectrum of malformations and reduction anomalies in one of the twins, which is perfused in a paradoxical retrograde fashion by a structurally normal 'pump' twin through a single artery-to-artery anatomosis².

\section{CASE REPORT}

A 23-year-old multigravida presented at four months of gestation in the outpatient department (OPD) of Kathmandu Medical College Teaching Hospital for regular antenatal care (ANC) visit where she was advised ultrasonography (USG) due to discrepancy between gestational age according to date and height of fundus. Detailed USG revealed twin pregnancy with a surviving twin which was structurally normal with a fetal biometry of 24 weeks of gestation, and the other dead twin was extremely edematous and no obvious foetal structures could be noted. Single placenta with single pocket of amniotic fluid with no separating membrane was noted

Address for correspondence

Dr. Babita Thapa

MD Resident

Department of Obstetrics and Gynaecology, Kathmandu Medical

College Teaching Hospital, Kathmandu, Nepal.

E-mail: bishalk@gmail.com
(Figure 1). On this basis, a diagnosis of twin pregnancy with one foetal demise was made. Patient was managed in OPD basis and fibrin degradation product (FDP) was checked once in two week interval and coagulation profile was done once in a week till 32 week of pregnancy. After three weeks she presented to OPD with absence of foetal movements for five days. Foetal heart sound (FHS) was not audible. Abdominal ultrasound scanning revealed both foetal demise. She was admitted and labour was induced with intravenous oxytocin. She had vaginal delivery. The first twin was male, weighing $1.6 \mathrm{~kg}$ with peeling of skin, distended abdomen (Figure 2) and second twin weighed $1.9 \mathrm{~kg}$ (Figure 3), upper portion contained soft globular mass, head and upper extremities were absent, external genitalia male type but poorly developed, the right foot had four toes and the left foot had three toes, the lower spinal column and lower leg bones were apparently normal. Autopsy revealed absence of foetal heart. Foetus was classified as acardius anceps with a cephalic pole containing some primitive embryonic structures. The placenta was single, monochorionic and weighed $500 \mathrm{gm}$ (Figure 4). Postpartum period was uneventful and she was discharged. 


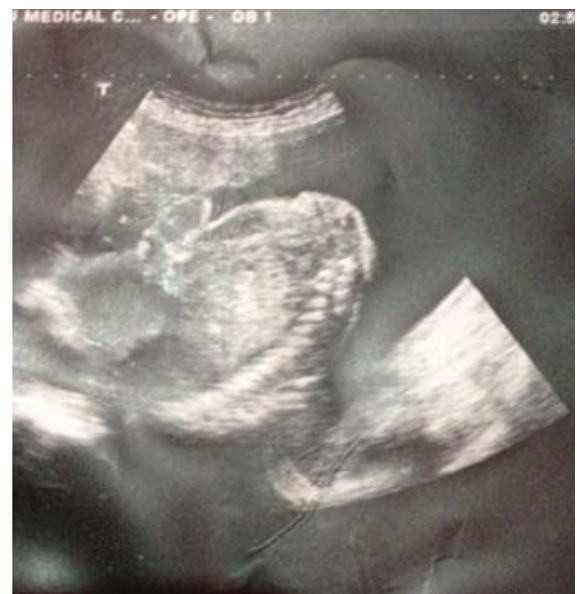

Figure 1: Single placenta with single pocket of amniotic fluid separating membrane

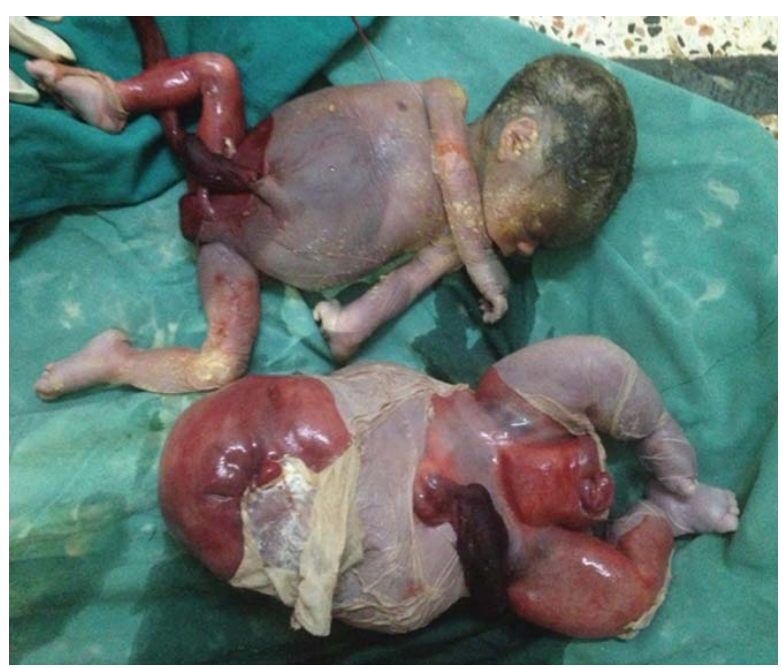

Figure 2: First twin male baby weighing $1.6 \mathrm{~kg}$ with peeling of skin, and distended abdomen

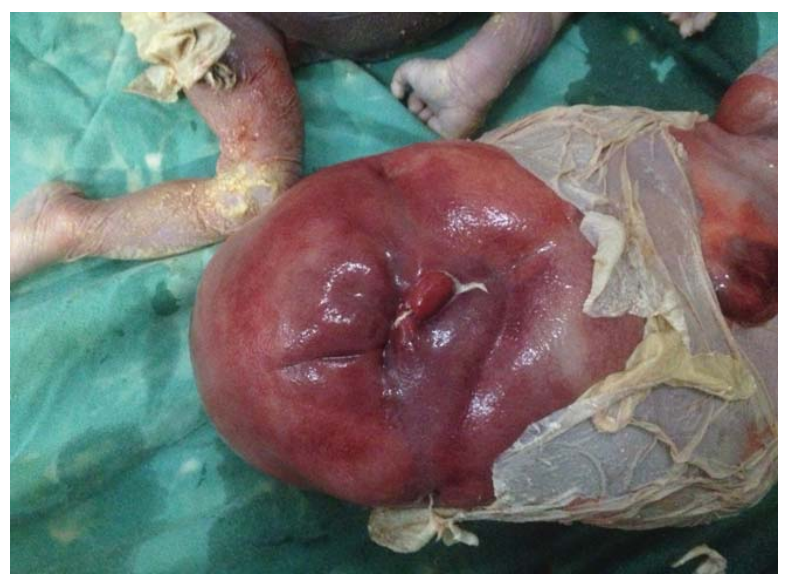

Figure 3: Second twin was acardiac and weighed $1.9 \mathrm{~kg}$

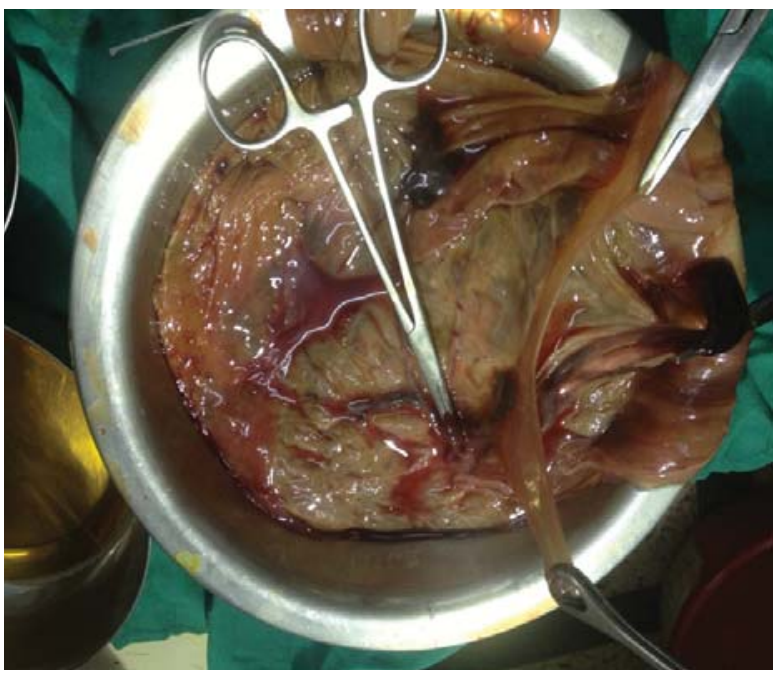

Figure 4: The placenta was single and weighed $500 \mathrm{gm}$ without intervening membrane

\section{DISCUSSION}

The first cases of acardia were reported by Benedetti in 1533 and Benedictus in 1539, and later by Geoffroy in 1836. Five hundred cases have been reported since ${ }^{3,4}$. The first classification of acardiac twins was presented by Das in 1902 and later modified by Napolitani $i^{2,4}$.The frequency of acardia is estimated to be one in 35,000 deliveries ${ }^{3}$. The distinction criteria most widely accepted today are morphological; that is, the presence or absence of head, body and cardiac tissue. Classified according to presence or absence of these structure:

1. Acardius acephalus: absence of head.

2. Acardius ancephs/paracephalus: some cranial structures and or neural tissue present.

3. Acardius acormus: only head present.

4. Acardius amorphus/anideus: no discernible cephalic or truncal structures.

The pathogenesis of TRAP is controversial, with two main pathogenetic hypotheses proposed ${ }^{[6]}$ :

1. Deep placental anastomoses in early embryogenesis cause malformation of the acardiac twin. The early pressure flow in one twin exceeds that of the other and leads to reversed circulation in the twin who exhibits perfusion.

2. A primary defect in embryogenesis in one twin leads to failure of cardiac development. The normal twin then perfuses the acardiac twin via artery-artery anastomoses. However, the anastomoses are not responsible for the cardiac anomaly. 
The mortality of the acardiac twin is $100 \%$, and the perinatal mortality of the pump twin is reported to be around $50 \%$. The poor outcome of the pump twin is primarily due to congestive heart failure $53 \%$, cord entanglement or prematurity ${ }^{4,7}$.

Detection of TRAP sequence in utero was first reported by Lehr and $\mathrm{DiRe}^{9}$ in 1978. Since then, much advancement in ultrasound technology has been implemented for detection of this anomaly. An acardiac twin should be suspected in all monochorionic, malformed foetuses with cystic hygroma, generalized edema, and an absent cardiac pulsation with a nonfunctioning heart. Similarly, an ultrasonography finding of twins revealing discordant or grotesque malformation along with reverse flow in the umbilical artery is usually diagnostic of an acardiac twin'11.

Early detection of TRAP sequence is of major importance because early evaluation and prompt intervention when indicated may improve the survival of the pump twin considerably. Indeed, early prophylactic treatment at 16 weeksof gestation in all cases of TRAP sequence is advocated by some authors ${ }^{9,10}$.

Many methods of management have been proposed. They include termination of pregnancy, serial ultrasound scans to monitor for signs of decompensation, medical management of polyhydramnios or management via serial amniocenteses, digitalization for prophylaxis or for treatment of cardiac failure, hysterotomy for removal of the anomalous twin, endoscopic clamping of the anomalous twin's cord, laser coagulation of the anastomosis and embolization of the circulation of the anomalous twin ${ }^{10-15}$. In our case, no antenatal therapy was performed. Attempted foeticide of an anomalous acardiac twin by cardiac puncture represents a danger to the normal twin: any substance injected into the acardiac circulation could circulate to the normal twin. Simpson et $\mathrm{al}^{11}$ successfully treated an acardiac pregnancy with Digoxin after there were sonographic signs of cardiac insufficiency of the pump twin. Quintero et $\mathrm{al}^{12}$ reported successful ligation of the acardiac twin's umbilical cord with an endoscopic technique. Grab et $\mathrm{al}^{13}$ attempted fibrin occlusion of the umbilical vein of an acardiac fetus, but both fetuses died. Ginsberg et $\mathrm{al}^{14}$ achieved term delivery of a healthy pump twin after section delivery of the acardiac foetus in the second trimester. Some complications resulting from these aggressive techniques are reported: premature delivery, risks of mid-trimester hysterotomy with regard to future fertility, and survival of the normal twin as well as twin embolization syndrome, which damages the normal twin and can result in mental retardation ${ }^{12-14}$.

Finally, the method of delivery is sometimes discussed because of the risk of dystocia in massively anomalous twins. Some cases of ruptured uterus have been reported ${ }^{2,9,10}$. In our case, the delivery was vaginal and no dystocia was observed. Umbilical Doppler can visualize the placental anastomoses as well as the reverse umbilical blood flow in the deformed foetus. A careful follow-up of the pregnancy is important in order to detect early cardiac failure and other complications.

\section{CONCLUSION}

This case indicates that acardia can be diagnosed by means of prenatal ultrasound in front of a monochorial twin pregnancy when one of the foetuses is deformed and has no cardiac activity. Heart failure and polyhydramnios as well as a Twin Weight Ratio greater than $50 \%$ are prognostic factors for the pump twin.

\section{REFERENCES}

1. Gross B, Petrikovsky B, Lane E. Twin reversed arterial perfusion (acardiac), amorphous [Internet]. 1994 May 8 [cited 2013 March 29]. Available from: http:// sonoworld.com/fetus/page.aspx?id=310

2. Izquierdo L, Smith J, Gilson G. Twin, acardiac, acephalus. Fetus. 1991;1:1-3.

3. Chanoufi MB, Ben Temime R, Masmoudi A, Ounaïssa K, Jebnoun S, Abid W, et al. Clinical and Anatomic Features of Acardiac Twins. Medical Principles and Practice. 2004 Nov-Dec;13(6):375-9.

4. Stiller RJ, Romero R, Pace S, Hobbins J. Prenatal identification of twin reversed arterial perfusion

syndrome in the first trimester. Am J Obstet Gynecol.1989 May;160(5 Pt 1):1194-6.

5. Athwal S, Millard K, Lakhoo K. Twin reversed arterial perfusion (TRAP) sequence in association with VACTERL association: a case report. J Med Case Reports. 2010 Dec 22; 4:411.

6. Moore TR, Gale S, Benirschke K. Perinatal outcome of forty-nine pregnancies complicated by acardiac twinning. Am J ObstetGynecol. 1990 Sep;163(3):90712.

7. Paek B, Goldberg JD, Albanese CT. Prenatal diagnosis. World J Surg. 2003 Jan;27(1):27-37. 
8. Bornstein E, Monteagudo A, Dong R, Schwartz $\mathrm{N}$, Timor-Tritsch IE. Detection of Twin Reversed Arterial Perfusion Sequence at the Time of FirstTrimester Screening. J Ultrasound Med. 2008 Jul;27(7):1105-9.

9. Rohilla M, Chopra S, Suri V, Aggarwal N, Vermani N. Acardiac-Acephalus Twins: A Report of 2 Cases and Review of Literature. Medscape J Med. 2008;10(8):200. Epub 2008 Aug 26.

10. Donnenfeld $A E$, van de Woestijne J, Craparo F, Smith CS, Ludomirsky A, Weiner S. The normal fetus of an acardiac twin pregnancy: Perinatal management based on echocardiographic and sonographic evaluation. Prenatal Diagnosis. 1991 Apr;11(4):23544.
11. Simpson PC, Trudinger BJ, Walker A, Baird PJ. The intrauterine treatment of fetal cardiac failure in a twin pregnancy with an acardiac, acephalic monster. Am J Obstet Gynecol.1983 Dec 1;147(7):842-4.

12. Quintero RA, Reich $H$, Puder KS, Bardicef M, Evans MI, Cotton DB, Romero R. Brief report: Umbilicalcord ligation of an acardiac twin by fetoscopy at 19 weeks of gestation. New Engl J Med. 1994 Feb 17;330(7):469-71.

13. Grab D, Schneider V, Keckstein J, Terinde R. Twin acardiac outcome. Fetus 1992;2(1):110-11.

14. Ginsberg NA, Applebaum M, Rabin SA, Caffarelli MA, Kuuspalu M, Daskal JL, et al. Term birth after mid-trimester hysterotomy and selective delivery of an acardiac twin. Am J Obstet Gynecol.1992 Jul;167(1):33-7. 